\title{
Monitoring by a Sensitive Liquid-Based Sampling Strategy Reveals a Considerable Reduction of Listeria monocytogenes in Smeared Cheese Production over 10 Years of Testing in Austria
}

\author{
Peter Zangerl ${ }^{1}$, Dagmar Schoder ${ }^{2}$, Frieda Eliskases-Lechner ${ }^{1}$, Abdoulla Zangana ${ }^{2}$, Elisabeth Frohner ${ }^{2}$, \\ Beatrix Stess1 ${ }^{2}$ (D) and Martin Wagner ${ }^{2,3, *}$ \\ 1 Higher Federal Teaching and Research Institute in Tyrol for Agriculture and Nutrition as well as Food and \\ Biotechnology, Rotholz 50, 6200 Strass im Zillertal, Austria; peter.zangerl@hblfa-tirol.at (P.Z.); \\ frieda.eliskases-lechner@hblfa-tirol.at (F.E.-L.) \\ 2 Unit of Food Microbiology, Institute of Food Safety, Food Technology and Veterinary Public Health, \\ Department for Farm Animals and Veterinary Public Health, University of Veterinary Medicine Vienna, \\ Veterinärplatz 1, 1210 Vienna, Austria; dagmar.schoder@vetmeduni.ac.at (D.S.); \\ Abdoulla.Zangana@vetmeduni.ac.at (A.Z.); Elisabeth.Frohner@vetmeduni.ac.at (E.F.); \\ Beatrix.Stessl@vetmeduni.ac.at (B.S.) \\ 3 Austrian Competence Center for Feed and Food Quality, Safety and Innovation (FFOQSI), Technopark C, \\ 3430 Tulln, Austria \\ check for \\ updates \\ * Correspondence: Martin.wagner@vetmeduni.ac.at; Tel.: +43-125-077-3500
}

Citation: Zangerl, P.; Schoder, D.; Eliskases-Lechner, F.; Zangana, A.; Frohner, E.; Stessl, B.; Wagner, M. Monitoring by a Sensitive Liquid-Based Sampling Strategy Reveals a Considerable Reduction of Listeria monocytogenes in Smeared Cheese Production over 10 Years of Testing in Austria. Foods 2021, 10, 1977. https://doi.org/10.3390/ foods10091977

Academic Editors:

Antonio Afonso Lourenco,

Catherine Burgess and Timothy Ells

Received: 21 July 2021

Accepted: 19 August 2021

Published: 24 August 2021

Publisher's Note: MDPI stays neutral with regard to jurisdictional claims in published maps and institutional affiliations.

Copyright: (C) 2021 by the authors. Licensee MDPI, Basel, Switzerland. This article is an open access article distributed under the terms and conditions of the Creative Commons Attribution (CC BY) license (https:// creativecommons.org/licenses/by/ $4.0 /)$.

\begin{abstract}
Most Austrian dairies and cheese manufacturers participated in a Listeria monitoring program, which was established after the first reports of dairy product-associated listeriosis outbreaks more than thirty years ago. Within the Listeria monitoring program, up to $800 \mathrm{~mL}$ of productassociated liquids such as cheese smear or brine are processed in a semi-quantitative approach to increase epidemiological sensitivity. A sampling strategy within cheese production, which detects environmental contamination before it results in problematic food contamination, has benefits for food safety management. The liquid-based sampling strategy was implemented by both industrial cheese makers and small-scale dairies located in the mountainous region of Western Austria. This report considers more than 12,000 Listeria spp. examinations of liquid-based samples in the 2009 to 2018 timeframe. Overall, the occurrence of L. monocytogenes in smear liquid samples was $1.29 \%$ and $1.55 \%$ ( $n=5043$ and $n=7194$ tested samples) for small and industrial cheese enterprises, respectively. The liquid-based sampling strategy for Listeria monitoring at the plant level appears to be superior to solid surface monitoring. Cheese smear liquids seem to have good utility as an index of the contamination of cheese up to that point in production. A modelling or validation process should be performed for the new semi-quantitative approach to estimate the true impact of the method in terms of reducing Listeria contamination at the cheese plant level.
\end{abstract}

Keywords: Listeria spp.; Listeria monocytogenes; prevalence; detection; monitoring; smear

\section{Introduction}

Cheese products have been a possible source of outbreaks of listeriosis for many decades, especially smeared cheeses and those made from raw milk [1-3] (https: / www. cdc.gov/Listeria/outbreaks/index.html; accessed on: 19 June 2021).

Cheeses made from goat or sheep milk are particularly likely to be L. monocytogenes positive (3.6-12.8\%) [4]. This is also evident from a search of the portal for Food and Feed Safety Alerts (RASSF), where 39/90 L. monocytogenes notifications relate to cheeses made from goat or sheep milk (https: / / webgate.ec.europa.eu/rasff-window/screen/search; accessed on: 19 June 2021). Significant genetic diversity was identified among L. monocytogenes strains through the use of molecular epidemiology methods [5-10]. Other research groups 
noticed an increased occurrence of hypervirulent L. monocytogenes strains of genetic lineage I (serovar $1 / 2 b, 4 b$, sequence type (ST) 1, ST4, ST6) in the dairy niche $[11,12]$. In addition, L. monocytogenes genetic lineage II strains (e.g., ST7, ST14, ST204; ST451), including hypovirulent types (ST121, ST9) were reported to persist in the dairy processing environment, potentially due to the intra- and inter-species exchange of mobile genetic elements [6,13-18].

An important role in environmental adaptation is played by highly conserved plasmids circulating worldwide in a distinctive L. monocytogenes gene pool [9,19-21]. These more complex epidemiological considerations have a direct impact on surveillance used to verify the effectiveness of L. monocytogenes controls within food safety management systems.

Although milk is usually subjected to a heating process prior to processing, cheese can become contaminated during several process steps such as pressing, curing, ripening, and during cutting and packaging [22,23].

In food processing environments (FPEs), contamination is often related to L. monocytogenes' colonization of surfaces, including in the dairy sector [24].

Own-check systems are applied with a focus on testing end products and samples from the production environment according to EC regulation 2073/2005 [25]. In food processing environments (FPEs), contamination is often related to L. monocytogenes' colonization of surfaces, including in the dairy sector [25].

In particular, newly built manufacturing plants or plants undergoing reconstruction measures are at high risk of being colonized with L. monocytogenes [26,27].

In cases where L. monocytogenes is detected on the end product at unacceptable levels, withdrawals from the market or recalls are implemented to protect the safety of the consumer.

To minimize the risk of process contamination during cheese ripening via the cheese smear, this liquid-based sampling strategy was established, which is also applicable to brine or drain water samples [28] (Figure 1). Since the majority of soft, semi-hard and hard cheeses in Austria are surface-ripened, smear liquids are, in most cases, collected after the smearing process. Compared to product-contact surface-sampling using frictionswabs, these liquids constitute a matrix that provides a much broader representation of the contamination status by including both cheese components and contact with surfaces inside of the production equipment, e.g., smear robots [29]. Sampling of a non-homogenous solid product creates real challenges in terms of consistency and representativeness. Listeria contamination is more likely on the surface rind than inside the cheese matrix. Moreover, sampling of a batch of individual cheeses has potential for statistical biases unless true randomisation is rigorously adhered to [3,30]. Sampling biases are major concerns and the degree of harmonization among procedures is usually low (sampling frequency and sampling sites are usually less well standardized) [31]. The implementation of preventive food safety concepts by tailored food sector-specific sampling procedures provokes a deepened insight of the FBOs into the operation-specific status of contamination and facilitates a comparison of scenarios.

The monitoring of cheeses produced without smearing focuses on sampling liquids including brine, wash water (water used to clean production devices such as trolleys or trays) or drain water. Sampling events depend on ripening time and batch size and should be performed twice per month. For small-scale dairies, the sampling frequency should ensure that every cheese is included at least once during ripening. After detection of L. monocytogenes and Listeria spp. by ISO enrichment methods, PCR-based species differentiation should be performed on typical Listeria colonies isolated on selective agar [32,33]. Persistence of L. innocua was shown to occur more frequently than persistence of L. monocytogenes and is, therefore, seen as an indicator of inadequate hygiene [34,35].

If L. monocytogenes is detected, rigorous sanitation of the facility is essential. Additionally, the sample number is increased and testing entails end products and further environmental samples (e.g., tanks, racks, conveyor belts and ventilation). This step includes a microbiological investigation post sanitation to verify the efficiency of the measures taken. If desired, a facility inspection audits the internal traffic management and checks 
other elements of the prerequisite programs (PrPs) that are in place, such as the maintenance of buildings and rooms. The hygienic status of production is, therefore, checked stepwise at all production areas. At the heart of the monitoring and surveillance approach is the range of sample volume that is tested: 600 to $800 \mathrm{~mL}$ (two labs involved, method slightly deviates), $100 \mathrm{~mL}, 10 \mathrm{~mL}$, and $1 \mathrm{~mL}$ of liquid (Figure 1). This semi-quantitative way of testing both low and high sample volumes substantially increases the epidemiological sensitivity of the method due to a higher quantity of sample matrix.

Indeed, directly after initial contamination of either the environment or the food, L. monocytogenes might be scarcely detectable in food business operations (FBOs) and testing of high volumes increases the likelihood of finding low contamination levels.

Therefore, the aim of this study was to present the alternative semi-quantitative liquid-based sampling strategy to increase the epidemiological sensitivity in the detection of L. monocytogenes and other Listeria species. For this purpose, the alternative method was implemented within the framework of Listeria monitoring, for both industrial cheese makers and small-scale dairies located in the mountainous region of Western Austria. By using this approach, more than 12,000 samples were tested during the period from 2009 to 2018 .

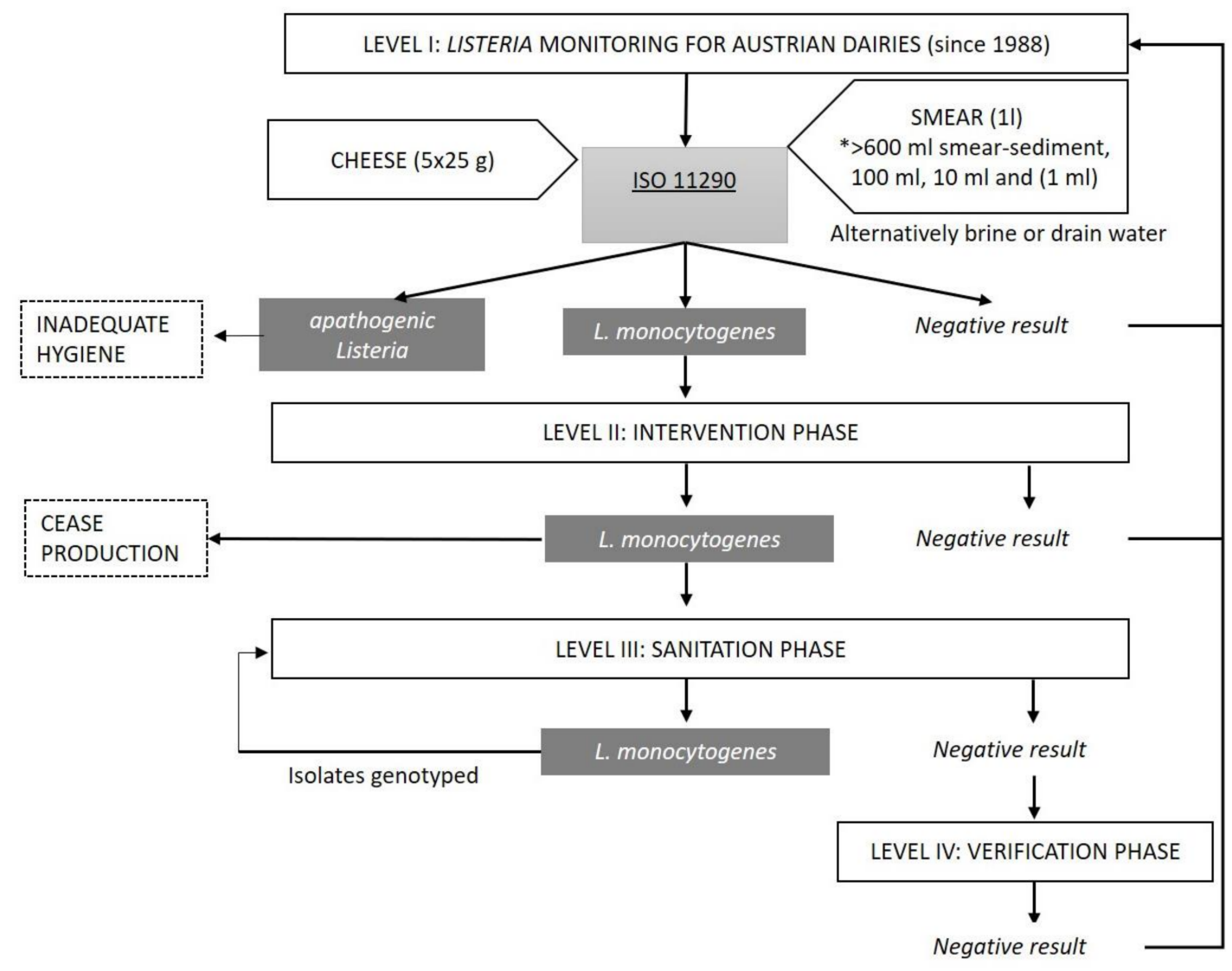

Figure 1. Flow chart displaying the structure of the Austrian Listeria monitoring and intervention program. Abbreviations: *, semi-quantitative liquid-based sample quantities.

\section{Materials and Methods}

\subsection{Materials}

Testing of cheeses for L. monocytogenes with a high level of confidence is limited by statistical biases. Investigation of smear liquid samples for monitoring purposes is a highly informative sampling strategy as all cheeses of a lot are usually treated with a smear liquid from the same tank. Therefore, analysis of the smear liquid allows for the contamination status of the entire cheese lot being stored for ripening. Sampling of smears is relatively 
simple and no cheese is damaged or spoiled by the sampling procedure [36] (Sampling scheme Figure 1).

\subsection{Companies}

According to the Austrian trade register for companies, around 80 professional cheese producers (this number does not include farm dairies directly marketing the product) exist in Austria (https://www.firmenbuchgrundbuch.at/ accessed on: 19 June 2021). Cheese making in Austria is conducted in operations that vary in size, ranging from small (products merchandised regionally) to industrial (products mostly merchandised across all of Austria and export markets such as the EU-27). Whereas some companies process a couple thousand liters of milk per year, industrial companies (spread over entire Austria) process tens of millions of liters. Small-scale cheese makers are mostly located in the Western parts of Austria. Many of them send their samples to the Higher Federal Teaching and Research Institute Tyrol (HBLFA) and, depending on the year, between 51 and 75 companies participate (see Table 1). The number of large industrial cheese producers that cooperate with the Institute of Food Safety, Food Technology and Veterinary Public Health (IFFV) ranges from 7 to 9 , and these companies produce more than $80 \%$ of the industrially produced smeared soft and semi-hard cheeses in Austria.

Table 1. Numbers of small and industrial food establishments (FBOs) that tested positive for L. monocytogenes and other Listeria spp., which participated in the Listeria monitoring program (2009-2018).

\begin{tabular}{ccccc}
\hline & \multicolumn{2}{c}{ Small FBOs (HBLFA) } & \multicolumn{2}{c}{ Industrial FBOs (IFFV) } \\
\hline Year & $\begin{array}{c}\text { L. monocytogenes } \\
\text { Positive/Total } \\
\boldsymbol{n}(\mathbf{\%})\end{array}$ & $\begin{array}{c}\text { Other listeria spp. } \\
\text { Positive/Total }\end{array}$ & $\begin{array}{c}\text { L. monocytogenes } \\
\text { Positive/Total } \\
\boldsymbol{n} \mathbf{( \% )}\end{array}$ & $\begin{array}{c}\text { Other listeria spp. } \\
\text { Positive/Total } \\
\boldsymbol{n} \mathbf{( \% )}\end{array}$ \\
\hline 2009 & $6 / 51(11.8 \%)$ & $7 / 51(13.7 \%)$ & $2 / 8(25.0 \%)$ & $2 / 8(25.0 \%)$ \\
2010 & $8 / 64(12.5 \%)$ & $10 / 64(15.6 \%)$ & $1 / 9(11.1 \%)$ & $2 / 9(22.2 \%)$ \\
2011 & $3 / 56(5.4 \%)$ & $8 / 56(14.3 \%)$ & $2 / 9(22.2 \%)$ & $3 / 9(33.3 \%)$ \\
2012 & $2 / 63(3.2 \%)$ & $13 / 63(20.6 \%)$ & $0 / 9(0 \%)$ & $4 / 9(44.4 \%)$ \\
2013 & $2 / 68(0.3 \%)$ & $11 / 68(16.2 \%)$ & $3 / 7(42.9 \%)$ & $3 / 9(42.9 \%)$ \\
2014 & $2 / 73(2.7 \%)$ & $14 / 73(19.2 \%)$ & $2 / 8(25.0 \%)$ & $5 / 8(62.5 \%)$ \\
2015 & $0 / 75(0 \%)$ & $13 / 75(17.3 \%)$ & $1 / 7(14.3 \%)$ & $2 / 7(28.6 \%)$ \\
2016 & $2 / 74(2.7 \%)$ & $6 / 74(8.1 \%)$ & $2 / 7(28.6 \%)$ & $2 / 7(28.6 \%)$ \\
2017 & $3 / 74(4.1 \%)$ & $12 / 74(16.2 \%)$ & $2 / 6(33.3 \%)$ & $2 / 6(33.3 \%)$ \\
2018 & $2 / 75(2.7 \%)$ & $11 / 75(14.7 \%)$ & $1 / 7(14.3 \%)$ & $2 / 7(28.6 \%)$ \\
\hline Mean & $3 / 67.3(4.5 \%)$ & $10.5 / 67.3(15.6 \%)$ & $1.6 / 7.7(20.8 \%)$ & $2 / 7.7(28.6 \%)$ \\
\hline
\end{tabular}

Abbreviations: FBOs, food business operations supervised by Higher Federal Teaching and Research Institute Tyrol (HBLFA) and Institute of Food Safety, Food Technology and Veterinary Public Health (IFFV); Listeria spp., Listeria species other than L. monocytogenes differentiated by iap PCR [32].

\subsection{Methods}

A total of 12,237 smear liquid samples were examined in the years 2009-2018 (see Table 1) by both testing labs. Liquid smear samples were collected in two-month intervals from industrial cheesemakers. Small FBOs collected smear samples during cheese ripening, representing comparatively smaller batches. Sample volumes of $1 \mathrm{~mL}$ (IFFV only), $10 \mathrm{~mL}$, $100 \mathrm{~mL}$ and $600 \mathrm{~mL}$ (IFFV) or $800 \mathrm{~mL}$ (HBLFA) are routinely investigated. The occurrence of $L$. monocytogenes in products, product-associated samples and in the processing environment is considered to be rather low and not equally distributed; therefore, the semi-quantitative enrichment protocol is assumed to increase the detection of L. monocytogenes in at least one of the enrichment steps [28]. One liter of liquid sample was divided into 4 preparations as follows: 600 or $800 \mathrm{~mL}$ were centrifuged at $4800 \mathrm{rpm}$ for $30 \mathrm{~min}$ at $4{ }^{\circ} \mathrm{C}$ (Beckman Coulter, Brea, CA, USA). The sediment was completely transferred into $1 \mathrm{~L}$ Half-Fraser broth (Biokar Diagnostics-Solabia Group, Pantin Cedex, France). Subsequent 
preparation steps of the semi-quantitative approach included $100 \mathrm{~mL}, 10 \mathrm{~mL}$, and $1 \mathrm{~mL}$ diluted 1:10 in Half-Fraser broth (Biokar Diagnostics-Solabia Group).

Sample enrichment in Half-Fraser broth and Fraser broth (both Biokar DiagnosticsSolabia Group) and strain isolation on Palcam Agar (Biokar Diagnostics-Solabia Group) and Listeria agar acc. Ottaviani and Agosti (ALOA; Merck KGaA, Darmstadt, Germany) was performed according to ISO 11290:1 [33]. In detail, for each semi-quantitative enrichment scenario (i.e., $600 / 800 \mathrm{~mL}, 100 \mathrm{~mL}, 10 \mathrm{~mL}, 1 \mathrm{~mL}$ ), following $24 \mathrm{~h}$ incubation at $30{ }^{\circ} \mathrm{C}$ in Half-Fraser broth, aliquots of $100 \mu \mathrm{L}$ were transferred to $10 \mathrm{~mL}$ Fraser broth and then incubated for $48 \mathrm{~h}$ at $37^{\circ} \mathrm{C}$.

In addition, at IFFV, polymerase chain reaction (PCR) assays targeting the hly gene (encoding the pore-forming cytolysin listeriolysin) and iap (invasion-associated protein p60) gene [31,37] were included for species confirmation (for technical details, see Asperger et al. [28]). This approach ensured that even a single L. monocytogenes colony that may have hidden in a plethora of other microorganisms, such as Bacillus spp. growing on PALCAM or chromogenic agar, would be detected [38].

The DNA extraction was performed directly from selective agar plates by rinsing the surface with $1 \mathrm{~mL}$ of $0.01 \mathrm{M}$ Tris $\mathrm{HCl}$ buffer (Sigma Aldrich Corp., St. Louis, MO, USA). The suspension was centrifuged for $5 \mathrm{~min}$ at $8000 \mathrm{rpm}$ and the pellet was suspended in $100 \mu \mathrm{L} 0.01 \mathrm{M}$ Tris HCl Buffer (Sigma Aldrich Corp.) and vortexed. In parallel, material from L. monocytogenes subcultures (1-2 colonies) was suspended in $100 \mu \mathrm{L}$ Tris $\mathrm{HCl}$ Buffer. Subsequently, $400 \mu \mathrm{L}$ Chelex ${ }^{\circledR}$ 100-Resin (BioRad, Hercules, CA, USA) was added to the bacterial suspension, heated for $10 \mathrm{~min}$ at $100{ }^{\circ} \mathrm{C}$ and centrifuged at $14,000 \mathrm{rpm}$ for $5 \mathrm{~s}$ [39]. The DNA supernatant was transferred to Maxymum Recovery tubes (VWR InternationalAvantor, Radnor, PA, USA) and stored at $-20^{\circ} \mathrm{C}$ before downstream processing $[31,37]$. The PCR-amplicons were electrophoretically separated in a $1.5 \%$ agarose gel containing $0.5 \times$ Tris-Borate-EDTA (TBE) buffer and $3.5 \mu \mathrm{L}$ peqGREEN DNA gel stain (VWR InternationalAvantor), at $120 \mathrm{~V}$ for $30 \mathrm{~min}$. The DNA standard Thermo Scientific ${ }^{\mathrm{TM}} \mathrm{GeneRuler}^{\mathrm{TM}} 100 \mathrm{bp}$ (Thermo Fisher Scientific Inc., Waltham, MA, USA) was applied for fragment length comparison. The electrophoresis gels were photographed under UV light exposure (GelDoc 2000, BioRad, Hercules) and saved in tiff format for further comparison.

\section{Results and Discussion}

Listeria contamination is an adverse event for many food business operations (FBOs), and the entire dairy sector suffers whenever outbreaks occur. A survey of technical managers in food processing plants on L. monocytogenes risk outcomes by Evans et al. [40]. revealed interesting assessments. Participants perceived a medium risk (on a scale from 1 to $10 ; 5.5$ ) of Listeria in their operations with a high level of control and a high level of responsibility. In this study, technical leaders expressed concern regarding L. monocytogenes and indicated that increased awareness of the pathogen would improve control actions. Installing Listeria environmental monitoring was considered essential in this regard [40].

A recent evaluation of monitoring approaches by Magdovitz et al. [41] showed that facilities prefer to test environmental monitoring zones 2 through 4 (non-food contact areas). Few facilities actively integrate raw material controls and intermediate products or product-associated samples into their sampling plan [41].

Many data are available for Listeria contamination scenarios in single FBOs, but little information is available for whole food production sectors such as smeared cheese manufacturing. EU baseline data on L. monocytogenes prevalence in cheese samples at the end of shelf-life showed a rate of $0.47 \%$, with $0.06 \%$ of samples exceeding the level of $100 \mathrm{cfu} / \mathrm{g}$ [42].

The few studies that are focused on data across food producers and batches are somehow comparable to our data and are cited in the following paragraph. Data on liquidbased sampling concepts are not available from the literature. Barría et al. [43] studied 546 cheese and milk samples to establish a monitoring system in Chilean cheese factories. L. monocytogenes was identified in 19 cheeses $(4.1 \%)$, with a prevalence similar to that 
reported in a Polish study (6.2\% L. monocytogenes, 370 samples) [44]. In both studies, the monitoring system focused on cheese samples as no food contact surface (FCS) or non-food contact surface (NFCS) samples were included in the sampling plan. Another Listeria spp. pilot study in PDO Taleggio cheese processing revealed a mean prevalence of $23.1 \%$ Listeria-positive samples ( $n=360$ samples). The ripening and cutting equipment were identified as high-risk areas for Listeria contamination [45]. Other short-term monitoring datasets were published, with an overall L. monocytogenes prevalence of $4.6 \%$ in various food sectors [46]. A larger dataset based on pathogen monitoring in small cheese processing plants (4430 samples; 6.03\% Listeria spp.) suggested running routine sampling plans for at least 6 months and then evaluating appropriate sampling sites inclusively for Listeria occurrence [34].

In general, cheese surfaces are more likely to be contaminated by L. monocytogenes than the internal areas of the cheese. This was also the outcome of a baseline study, conducted at a national level, where Gorgonzola and Taleggio were the most frequently contaminated cheeses. Transmission of L. monocytogenes from contaminated cheese rind to the cheese interior during cutting or packaging is possible [47]. Therefore, productassociated samples, such as smear liquids and surface scrapings, should be considered in a Listeria monitoring program.

Our data from the cheese smear liquid-based monitoring showed, in small cheese producers (mainly soft and semi-soft cheeses), an average Listeria spp. (other than L. monocytogenes) and L. monocytogenes contamination of $15.6 \%$ and $4.5 \%$, respectively, During the sampling period, an average of 67 out of 75 FBOs were Listeria spp. positive. Numbers for industrial cheesemakers show that an average of eight FBOs participated in the program, where means of $20.8 \%$ L. monocytogenes and $28.6 \%$ Listeria spp. (other than L. monocytogenes) were detected.

The L. monocytogenes contamination ranged from 0 to $12.5 \%$ and from 0 to $33.3 \%$ in small and industrial FBOs during 2009 to 2018, respectively. Listeria spp. other than L. monocytogenes, which were differentiated by the PCR approach [32], ranged from 8.1 to $20.6 \%$ in small FBOs and from 22.2 to $44.4 \%$ in industrial FBOs (Table 1), indicating that the latter was more highly contaminated with the potential pathogen. The industrial FBOs were higher contaminated with L. monocytogenes in comparison to small FBOs. Similar observations were made by Muhterem et al. [25], where the FPE of industrial cheesemakers indicated a higher L. monocytogenes contamination of up to $26 \%$ compared to farm cheesemakers (up to 6.4\%). In total, Listeria spp. was detected in $4.19 \%$ (513 out of 12.237) of all smear liquid samples examined, whereas the percentage of L. monocytogenespositive samples was $1.45 \%$ (178 out of 12.237 samples). The higher frequency of Listeria spp. (other than L. monocytogenes) contamination is an important indicator of necessary hygiene improvement measures to prevent L. monocytogenes from successfully establishing itself as a zoonotic pathogen in a FPE [48]. This value for Listeria spp.-associated contamination was substantially lower in comparison to samples that were tested at the IFFV between 1990 and 1999 (industrial cheese makers only: 14.09\%) [28]. If calculated based on years, the prevalence of L. monocytogenes in smears was 0-4.4\% (average: $1.29 \%$ ) and 0-6\% (average: $1.55 \%$ ) for the small and the industrial cheese establishments, respectively (see Table 2). 
Table 2. The number of smear liquid samples tested and the rate of L. monocytogenes and other Listeria spp.-positive results found.

\begin{tabular}{|c|c|c|c|c|c|c|c|c|c|c|}
\hline \multirow[t]{2}{*}{ Year } & \multicolumn{5}{|c|}{ Small Dairys (Western Austria; HBLFA) } & \multicolumn{5}{|c|}{ Industrial Cheesemakers (IFFV) } \\
\hline & $n$ & L. monocytogenes & $(\%)$ & $\begin{array}{c}\text { Other } \\
\text { Listeria spp. }\end{array}$ & $(\%)$ & $n$ & L. monocytogenes & $(\%)$ & $\begin{array}{c}\text { Other } \\
\text { Listeria spp. }\end{array}$ & $(\%)$ \\
\hline 2009 & 475 & 19 & 4 & 13 & 2.7 & 189 & 5 & 2.1 & 13 & 6.9 \\
\hline 2010 & 620 & 27 & 4.4 & 12 & 1.9 & 503 & 3 & 0.6 & 68 & 13.5 \\
\hline 2011 & 394 & 3 & 0.8 & 10 & 2.5 & 881 & 12 & 1.4 & 27 & 3.1 \\
\hline 2012 & 441 & 2 & 0.5 & 23 & 5.2 & 774 & 0 & 0.0 & 70 & 9.0 \\
\hline 2013 & 441 & 3 & 0.7 & 21 & 4.8 & 711 & 3 & 0.4 & 22 & 3.1 \\
\hline 2014 & 516 & 2 & 0.4 & 22 & 4.3 & 702 & 2 & 0.3 & 19 & 2.7 \\
\hline 2015 & 523 & 0 & 0.0 & 21 & 4.0 & 1535 & 24 & 1.6 & 14 & 0.9 \\
\hline 2016 & 512 & 3 & 0.6 & 9 & 1.8 & 634 & 8 & 1.3 & 14 & 2.2 \\
\hline 2017 & 544 & 3 & 0.6 & 24 & 4.4 & 752 & 45 & 6.0 & 46 & 6.1 \\
\hline 2018 & 577 & 5 & 0.9 & 14 & 2.4 & 513 & 9 & 1.8 & 51 & 9.9 \\
\hline Total & 5043 & 67 & 1.29 & 169 & 3.4 & 7194 & 111 & 1.55 & 344 & 5.74 \\
\hline
\end{tabular}

Abbreviations: Small dairys and industrial cheesemakers supervised by Higher Federal Teaching and Research Institute Tyrol (HBLFA) and Institute of Food Safety, Food Technology and Veterinary Public Health (IFFV); Listeria spp., Listeria species other than L. monocytogenes differentiated by iap PCR [32].

This is of interest as the industrial cheese producers included in this study mainly used pasteurized milk, while the small producers tended to use raw milk for the production of traditional specialty cheeses.

Since the occurrence of L. monocytogenes contamination was similar for both categories (Table 2), we confirmed that heat treatment of milk had little impact on the presence of L. monocytogenes in the smears and that, in the majority of our observations, cheese is more likely to become contaminated after coagulation [18,35,49].

Inclusion of high sample volumes was found to increase the detection sensitivity of the method as applied at both institutes. At HBLFA, $11.98 \%$ of samples tested positive in $800 \mathrm{~mL}$ and $100 \mathrm{~mL}$ but not in $10 \mathrm{~mL}$, and $19.4 \%(n=13)$ of all positive findings were found in the highest sample volume only (data not shown). Only $26.9 \%(n=18)$ of all samples tested positive in $800 \mathrm{~mL}, 100 \mathrm{~mL}$ and $10 \mathrm{~mL}$. From the fact that more than $30 \%$ of the positive events were observed in volumes of $\geq 100 \mathrm{~mL}$ only, we conclude that $L$. monocytogenes contamination levels are often very low at the beginning of a contamination event. Data also suggest that testing only $25 \mathrm{~mL}$ of cheese-associated fluids (which is commonly the case in other countries) does not provide enough epidemiologic sensitivity to detect lowlevel contamination.

This assumption would be interesting to compare in the performance testing of the ISO method versus alternative liquid-based sampling strategies with higher sample volumes. Some samples revealed L. monocytogenes detection in either $10 \mathrm{~mL}$ or $100 \mathrm{~mL}$ but not in $800 \mathrm{~mL}$. This effect could have been caused by a not-yet-understood antiListerial potential of the smear microbiota in some samples, testing too soon following the use of protective cultures against L. monocytogenes (e.g., phages), and extremely high numbers of accompanying flora after centrifugation of 600 and $800 \mathrm{~mL}$, respectively [50-52]. Unpublished results on the inhibitory effects of smear samples on Listeria showed a highly variable pattern, ranging from a decrease in numbers of L. monocytogenes by 3 log units in some samples to a proliferation capacity of up to $4 \log \mathrm{CFU} / \mathrm{mL}$ in other samples (Part, pers. communication). We conclude that testing of high volumes only is not sufficient to detect a contamination event; therefore, the more extensive approach of testing more than one sampling volume should be incorporated. Findings from small cheese producers were consistent with results that were found with samples originating from industrial cheese plants. Twenty-four percent $(n=22)$ of positive results were found in the high sample volume $(600 \mathrm{~mL})$ only. As many as $16.5 \%$ of smear liquid samples were found to be positive in sample volumes of $600 \mathrm{~mL}$ and $100 \mathrm{~mL}$. Another $15.4 \%$ of the samples were positive in $600 \mathrm{~mL}, 100 \mathrm{~mL}$ and $10 \mathrm{~mL}$. The smear monitoring conducted at IFFV also incorporated 
$1 \mathrm{~mL}$ samples. Being positive in $1 \mathrm{~mL}$ was thought to be a cause for concern as a higher number of L. monocytogenes might be present in the smear liquid and, subsequently, on the cheese. In $12 \%(n=11)$ of all positive smear liquid samples, L. monocytogenes was found in all sample volumes $(600 \mathrm{~mL}, 100 \mathrm{~mL}, 10 \mathrm{~mL}$ and $1 \mathrm{~mL})$. As with the data provided by HBFLA, the findings at IFFV are inconclusive in some cases. In $24 \%$ of the positive results, L. monocytogenes was detected in $100 \mathrm{~mL}$ of sample volume only.

Although the first food-associated outbreaks were reported from USA and Canada in the early 1980s, a game changer for the national dairy industry was the Swiss Vacherin Mont d'Or outbreak in 1983-1987 [53]. Austrian companies began testing cheese brine and smears in 1988 to improve L. monocytogenes detection during production. From 1992 to 1994 , a 30 to $40 \%$ positive test rate for $L$. monocytogenes was observed. Within a decade of increased measures, prevalence decreased to a detection rate of $<5 \%$ [28]. The liquid-based sampling strategy also shows successful detection of L. monocytogenes in our approach, and possibly a positive impact in terms of avoiding false negatives and product withdrawals or recalls. This positive development of improved awareness of possible L. monocytogenes contamination occurred in spite of an ongoing restructuring of the dairy sector in Austria, which reduced the number of industrial cheese dairies from $>50$ in 1990 to less than 10 in 2019.

In line with the economic growth of some major players, the amount of produced cheese (soft, semisoft and hard cheese) quintupled from 1990 to $2019(<30,000$ tons in 1995 to 131,000 tons per year in 2018).

The monitoring of results such as those achieved by the Listeria monitoring program is a prerequisite for the timely detection of potential safety hazards, including the contamination of cheese environments with $L$. monocytogenes. Frequent monitoring aids early L. monocytogenes detection, and prevents contamination and the placing of contaminated food on the market [31]. That there is a considerable likelihood for introduction is evidenced by the fact that, at least once, positive Listeria spp. results were revealed over all the years from a majority of the participants in the program. If contamination remains unaffected by routine hygiene measures, Listeria is spread within the production area through daily in-plant manipulations.

In the long run, Listeria spp. colonizes niches within the FBO, where the hygienic pressure is not high enough to prevent them from surviving, thereby allowing Listeria spp. to survive.

Experience in recent years has repeatedly confirmed that testing higher sample volumes effectively complements other hygiene inspection techniques, such as swabbing or contact sliding.

In accordance with the testing of product-associated liquids, environment-derived liquid samples such as drain water samples encompass the contamination status of large plant areas. The use of large volumes of liquid in our semi-quantitative sampling approach potentially reduces the false negative test results that can occur when using smaller volumes or simple contact sliding.

Investigation of smear liquid is beneficial as this substrate is used on entire cheese batches for extended production periods. Therefore, with respect to cheese processing, the microbiological investigation of smear liquid is an appropriate parameter in any safety program dealing with smear-ripened cheeses.

Preventing foodborne hazards along the food processing chain is supported by an intelligent sampling strategy that may differ among food sectors and professionals. For L. monocytogenes environmental testing, mostly swab and sponge-based friction sampling methods are used [54]. The decrease in the L. monocytogenes detection rate, as seen in Austrian cheese factories in recent years, coincides with an increased understanding and acceptance of food safety parameters by the cheese producers, which was in part contributed to by a high-profile cheese-borne outbreak of listeriosis [55].

The consideration of a preventive QS certification system is important within the context of the explicit obligations placed on food business operators through EU food law 
to undertake such monitoring both against microbiological criteria in food and, in the case of L. monocytogenes, within the food production environment, to validate the effectiveness of their food safety management systems. Official control analyses serve a different purpose, and are required to be risk based, as opposed to representing food production, which generally occurs at much lower frequency. For example, in Austria, 35,000 food samples are annually taken by public authorities by a factor of $>5$.

\section{Conclusions}

The increasing trend of listeriosis incidence in Austria, from a mean value of 0.17 per 100,000 inhabitants from 2000 to 2005 to a mean value of 0.4 from 2009 to 2018 (Austrian Agency for Health and Food Safety-AGES, 2018; https:/ / www.ages.at/download/0/0/c38f0d95e095 fe7e74162ddae9052a4c532450db / fileadmin/AGES2015/Themen/Krankheitserreger_Dateien/ Zoonosen/Zoonosenbroschuere_2018_1o_Din-A4_BF.pdf; accessed on 9 June 2021), emphasizes the requirements for effective strategies that meet the control needs of the national public health system and food manufacturers. The liquid-based sampling strategy within a Listeria monitoring program at the plant level appears to be superior to solid surface monitoring. Cheese smear liquids seem to have good utility as an index of the contamination of cheese up to that point in production. Multiple volumes of liquid phase, as implemented with our semi-quantitative approach, seem to improve the likelihood of detection, which is consistent with improved epidemiological sensitivity. Monitoring results show a downward trend in Listeria prevalence within this matrix, at least for industrial cheese production, which is thereby consistent with improved hygiene in cheese processing environments and cheese products. Modeling or performance testing of this new semi-quantitative approach against the ISO method would be important to more concretely assess the potential for Listeria minimization in cheese production.

Author Contributions: P.Z. and M.W. conceived and designed the experiments. F.E.-L., A.Z. and E.F. performed the experiments. P.Z., M.W., D.S. and B.S. analyzed the data. P.Z. and M.W. drafted the manuscript. B.S. and D.S. reviewed the manuscript. All authors have read and agreed to the published version of the manuscript.

Funding: This work was partly funded by the Austrian Competence Centre for Feed and Food Quality, Safety and Innovation (FFoQSI). The COMET-K1 competence centre FFoQSI is funded by the Austrian ministries BMVIT and BMDW, and the Austrian provinces Niederoesterreich, Upper Austria and Vienna, within the scope of COMET-Competence 301 Centers for Excellent Technologies. The COMET program is handled by the Austrian Research Promotion Agency FFG.

Institutional Review Board Statement: Not applicable.

Informed Consent Statement: Not applicable.

Data Availability Statement: Not applicable.

Acknowledgments: We thank the FBOs for their constructive cooperation. Furthermore, we thank Clair Firth for proofreading the manuscript.

Conflicts of Interest: The authors declare no conflict of interest.

\section{References}

1. Desai, A.N.; Anyoha, A.; Madoff, L.C.; Lassmann, B. Changing epidemiology of Listeria monocytogenes outbreaks, sporadic cases, and recalls globally: A review of ProMED reports from 1996 to 2018. Int. J. Infect. Dis. 2019, 84, 48-53. [CrossRef] [PubMed]

2. Melo, J.; Andrew, P.; Faleiro, M. Listeria monocytogenes in cheese and the dairy environment remains a food safety challenge: The role of stress responses. Food Res. Int. 2015, 67, 75-90. [CrossRef]

3. Rudolf, M.; Scherer, S. High incidence of Listeria monocytogenes in European red smear cheese. Int. J. Food Microbiol. 2001, 63, 91-98. [CrossRef]

4. Gonzales-Barron, U.; Gonçalves-Tenório, A.; Rodrigues, V.; Cadavez, V. Foodborne pathogens in raw milk and cheese of sheep and goat origin: A meta-analysis approach. Curr. Opin. Food Sci. 2017, 18, 7-13. [CrossRef] 
5. Amato, E.; Filipello, V.; Gori, M.; Lomonaco, S.; Losio, M.N.; Parisi, A.; Huedo, P.; Knabel, S.J.; Pontello, M. Identification of a major Listeria monocytogenes outbreak clone linked to soft cheese in Northern Italy-2009-2011. BMC Infect. Dis. 2017, 17, 1-7. [CrossRef]

6. Cabal, A.; Pietzka, A.; Huhulescu, S.; Allerberger, F.; Ruppitsch, W.; Schmid, D. Isolate-Based Surveillance of Listeria monocytogenes by Whole Genome Sequencing in Austria. Front. Microbiol. 2019, 10, 2282. [CrossRef]

7. Finazzi, G.; Filipello, V.; Gori, M.; Scaltriti, E.; Bracchi, C.; Menozzi, I.; Tanzi, E.; Bolzoni, L. A Listeria monocytogenes ST325 clone is widespread in the Lombardy Region dairy processing plants. Eur. J. Public Health 2020, 30 (Suppl. 5), 166-229. [CrossRef]

8. Nüesch-Inderbinen, M.; Bloemberg, G.V.; Müller, A.; Stevens, M.J.; Cernela, N.; Kollöffel, B.; Stephan, R. Listeriosis Caused by Persistence of Listeria monocytogenes Serotype $4 \mathrm{~b}$ Sequence Type 6 in Cheese Production Environment. Emerg. Infect. Dis. 2021, 27, 284-288. [CrossRef]

9. Muhterem-Uyar, M.; Ciolacu, L.; Wagner, K.-H.; Wagner, M.; Schmitz-Esser, S.; Stessl, B. New Aspects on Listeria monocytogenes ST5-ECVI Predominance in a Heavily Contaminated Cheese Processing Environment. Front. Microbiol. 2018, 9, 64. [CrossRef]

10. Schmitz-Esser, S.; Müller, A.; Stessl, B.; Wagner, M. Genomes of sequence type 121 Listeria monocytogenes strains harbor highly conserved plasmids and prophages. Front. Microbiol. 2015, 6, 380. [CrossRef]

11. Bechtel, T.D.; Gibbons, J.G. Population Genomic Analysis of Listeria monocytogenes From Food Reveals Substrate-Specific Genome Variation. Front. Microbiol. 2021, 12. [CrossRef]

12. Maury, M.M.; Bracq-Dieye, H.; Huang, L.; Vales, G.; Lavina, M.; Thouvenot, P.; Disson, O.; Leclercq, A.; Brisse, S.; Lecuit, M. Hypervirulent Listeria monocytogenes clones' adaption to mammalian gut accounts for their association with dairy products. Nat. Commun. 2019, 10, 1-13. [CrossRef]

13. Castro, H.; Douillard, F.; Korkeala, H.; Lindström, M. Diverse mobile genetic elements support the persistence of Listeria monocytogenes on dairy farms. bioRxiv 2021. [CrossRef]

14. Guidi, F.; Orsini, M.; Chiaverini, A.; Torresi, M.; Centorame, P.; Acciari, V.; Salini, R.; Palombo, B.; Brandi, G.; Amagliani, G.; et al. Hypo- and Hyper-Virulent Listeria monocytogenes Clones Persisting in Two Different Food Processing Plants of Central Italy. Microorganisms 2021, 9, 376. [CrossRef]

15. Matereke, L.T.; Okoh, A.I. Listeria monocytogenes Virulence, Antimicrobial Resistance and Environmental Persistence: A Review. Pathogens 2020, 9, 528. [CrossRef] [PubMed]

16. Palaiodimou, L.; Fanning, S.; Fox, E.M. Genomic insights into persistence of Listeria species in the food processing environment. J. Appl. Microbiol. 2021. [CrossRef] [PubMed]

17. Rychli, K.; Wagner, E.M.; Ciolacu, L.; Zaiser, A.; Tasara, T.; Wagner, M.; Schmitz-Esser, S. Comparative genomics of human and non-human Listeria monocytogenes sequence type 121 strains. PLoS ONE 2017, 12, e0176857. [CrossRef]

18. Stessl, B.; Fricker, M.; Fox, E.; Karpiskova, R.; Demnerová, K.; Jordan, K.; Ehling-Schulz, M.; Wagner, M. Collaborative Survey on the Colonization of Different Types of Cheese-Processing Facilities with Listeria monocytogenes. Foodborne Pathog. Dis. 2014, 11, 8-14. [CrossRef] [PubMed]

19. Jennison, A.V.; Masson, J.J.; Fang, N.-X.; Graham, R.M.; Bradbury, M.; Fegan, N.; Gobius, K.; Graham, T.M.; Guglielmino, C.; Brown, J.L.; et al. Analysis of the Listeria monocytogenes Population Structure among Isolates from 1931 to 2015 in Australia. Front. Microbiol. 2017, 8, 603. [CrossRef]

20. Naditz, A.L.; Dzieciol, M.; Wagner, M.; Schmitz-Esser, S. Plasmids contribute to food processing environment-associated stress survival in three Listeria monocytogenes ST121, ST8, and ST5 strains. Int. J. Food Microbiol. 2019, 299, 39-46. [CrossRef] [PubMed]

21. Schmitz-Esser, S.; Anast, J.M.; Cortes, B.W. A Large-Scale Sequencing-Based Survey of Plasmids in Listeria monocytogenes Reveals Global Dissemination of Plasmids. Front. Microbiol. 2021, 12, 510. [CrossRef] [PubMed]

22. Falardeau, J.; Trmčić, A.; Wang, S. The occurrence, growth, and biocontrol of Listeria monocytogenes in fresh and surface-ripened soft and semisoft cheeses. Compr. Rev. Food Sci. Food Saf. 2021. [CrossRef] [PubMed]

23. Sauders, B.D.; D'Amico, D.J. Listeria monocytogenes cross-contamination of cheese: Risk throughout the food supply chain. Epidemiology Infect. 2016, 144, 2693-2697. [CrossRef] [PubMed]

24. Muhterem-Uyar, M.; Dalmasso, M.; Bolocan, A.S.; Hernandez, M.; Kapetanakou, A.; Kuchta, T.; Manios, S.G.; Melero, B.; Minarovičová, J.; Nicolau, A.I.; et al. Environmental sampling for Listeria monocytogenes control in food processing facilities reveals three contamination scenarios. Food Control 2015, 51, 94-107. [CrossRef]

25. Commission Regulation (EC) No 2073/2005 on microbiological criteria for foodstuffs. Off. J. Eur. Union L. 2005, $338,1-26$.

26. Alvarez-Molina, A.; Cobo-Díaz, J.F.; López, M.; Prieto, M.; de Toro, M.; Alvarez-Ordóñez, A. Unraveling the emergence and population diversity of Listeria monocytogenes in a newly built meat facility through whole genome sequencing. Int. J. Food Microbiol. 2021, 340, 109043. [CrossRef]

27. Melero, B.; Stessl, B.; Manso, B.; Wagner, M.; Esteban-Carbonero, Ó.J.; Hernandez, M.; Rovira, J.; Rodriguez-Lázaro, D. Listeria monocytogenes colonization in a newly established dairy processing facility. Int. J. Food Microbiol. 2019, 289, 64-71. [CrossRef]

28. Asperger, H.; Wagner, M.; Brandl, E. An approach towards public health and foodborne human listeriosis-The Austrian Listeria monitoring. Berl. Munchener Tierarztliche Wochenschr. 2001, 114, 446-452. [PubMed]

29. Jordan, K.; Leong, D.; Ordóñez, A.Á. National Listeria Monitoring Programmes. In Listeria monocytogenes in the Food Processing Environment; Springer: Cham, Germany, 2015; pp. 73-75.

30. Schvartzman, M.S.; Gonzalez-Barron, U.; Butler, F.; Jordan, K. Modeling the growth of Listeria monocytogenes on the surface of smear- or mold-ripened cheese. Front. Cell. Infect. Microbiol. 2014, 4, 90. [CrossRef] 
31. Spanu, C.; Jordan, K. Listeria monocytogenes environmental sampling program in ready-to-eat processing facilities: A practical approach. Compr. Rev. Food Sci. Food Saf. 2020, 19, 2843-2861. [CrossRef]

32. Bubert, A.; Hein, I.; Rauch, M.; Lehner, A.; Yoon, B.; Goebel, W.; Wagner, M. Detection and Differentiation of Listeria spp. by a Single Reaction Based on Multiplex PCR. Appl. Environ. Microbiol. 1999, 65, 4688-4692. [CrossRef]

33. ISO 11290-1:2017 Microbiology of the Food Chain-Horizontal Method for the Detection and Enumeration of Listeria Monocytogenes and of Listeria Spp.-Part 1: Detection Method; International Organization for Standardization: Geneva, Switzerland, 2017.

34. Beno, S.M.; Stasiewicz, M.; Andrus, A.D.; Ralyea, R.D.; Kent, D.J.; Martin, N.H.; Wiedmann, M.; Boor, K. Development and Validation of Pathogen Environmental Monitoring Programs for Small Cheese Processing Facilities. J. Food Prot. 2016, 79, 2095-2106. [CrossRef]

35. Kaszoni-Rückerl, I.; Mustedanagic, A.; Muri-Klinger, S.; Brugger, K.; Wagner, K.-H.; Wagner, M.; Stessl, B. Predominance of Distinct Listeria Innocua and Listeria monocytogenes in Recurrent Contamination Events at Dairy Processing Facilities. Microorganisms 2020, 8, 234. [CrossRef]

36. Wagner, M.; Stessl, B. Sampling the Food-Processing Environment: Taking Up the Cudgel for Preventive Quality Management in Food Processing (FP). In Listeria monocytogenes; Humana: New York, NY, USA, 2021; pp. 233-242.

37. Border, P.M.; Howard, J.J.; Plastow, G.; Siggens, K.W. Detection of Listeria species and Listeria monocytogenes using polymerase chain reaction. Lett. Appl. Microbiol. 1990, 11, 158-162. [CrossRef]

38. Stessl, B.; Luf, W.; Wagner, M.; Schoder, D. Performance testing of six chromogenic ALOA-type media for the detection of Listeria monocytogenes. J. Appl. Microbiol. 2009, 106, 651-659. [CrossRef]

39. Walsh, P.S.; Metzger, D.A.; Higuchi, R. Chelex 100 as a Medium for Simple Extraction of DNA for PCR-Based Typing from Forensic Material. BioTechniques 2013, 54, 134-139. [CrossRef] [PubMed]

40. Evans, E.; Samuel, E.; Redmond, E.; Taylor, H. Exploring Listeria monocytogenes perceptions in small and medium sized food manufacturers: Technical leaders' perceptions of risk, control and responsibility. Food Control 2021, 126, 108078. [CrossRef]

41. Magdovitz, B.F.; Gummalla, S.; Thippareddi, H.; Harrison, M.A. Evaluating Environmental Monitoring Protocols for Listeria spp. and Listeria monocytogenes in Frozen Food Manufacturing Facilities. J. Food Prot. 2019, 83, 172-187. [CrossRef]

42. European Food Safety Authority-Efsa. Analysis of the baseline survey on the prevalence of Listeria monocytogenes in certain ready-to-eat foods in the EU, 2010-2011 Part A: Listeria monocytogenes prevalence estimates. EFSA J. 2013, 11. [CrossRef]

43. Barría, C.; Singer, R.S.; Bueno, I.; Estrada, E.; Rivera, D.; Ulloa, S.; Fernández, J.; Mardones, F.O.; Moreno-Switt, A.I. Tracing Listeria monocytogenes contamination in artisanal cheese to the processing environments in cheese producers in southern Chile. Food Microbiol. 2020, 90, 103499. [CrossRef]

44. Pyz-Łukasik, R.; Gondek, M.; Winiarczyk, D.; Michalak, K.; Paszkiewicz, W.; Piróg-Komorowska, A.; Policht, A.; Ziomek, M. Occurrence of Listeria monocytogenes in Artisanal Cheeses from Poland and Its Identification by MALDI-TOF MS. Pathogens 2021, 10, 632. [CrossRef]

45. Tirloni, E.; Bernardi, C.; Pomilio, F.; Torresi, M.; De Santis, E.P.L.; Scarano, C.; Stella, S. Occurrence of Listeria spp. and Listeria monocytogenes Isolated from PDO Taleggio Production Plants. Foods 2020, 9, 1636. [CrossRef]

46. Leong, D.; Alvarez-Ordóñez, A.; Ejordan, K. Monitoring occurrence and persistence of Listeria monocytogenes in foods and food processing environments in the Republic of Ireland. Front. Microbiol. 2014, 5, 436. [CrossRef]

47. Iannetti, L.; Acciari, V.A.; Antoci, S.V.; Addante, N.; Bardasi, L.; Bilei, S.; Calistri, P.; Cito, F.; Cogoni, P.; D’Aurelio, R.; et al. Listeria monocytogenes in ready-to-eat foods in Italy: Prevalence of contamination at retail and characterisation of strains from meat products and cheese. Food Control. 2016, 68, 55-61. [CrossRef]

48. Rückerl, I.; Muhterem-Uyar, M.; Muri-Klinger, S.; Wagner, K.-H.; Wagner, M.; Stessl, B.L. monocytogenes in a cheese processing facility: Learning from contamination scenarios over three years of sampling. Int. J. Food Microbiol. 2014, 189, 98-105. [CrossRef]

49. Schaffner, E.; Mühlemann, M.; Spahr, U.; Schällibaum, M. Quantification of the probability of milk contamination by Listeria monocytogenes during manufacture of hard cheese. Rev. D'epidemiologie et de Sante Publique 2003, 51, 493-503.

50. Fister, S.; Fuchs, S.; Stessl, B.; Schoder, D.; Wagner, M.; Rossmanith, P. Screening and characterisation of bacteriophage P100 insensitive Listeria monocytogenes isolates in Austrian dairy plants. Food Control 2016, 59, 108-117. [CrossRef]

51. Bockelmann, W.; Koslowsky, M.; Goerges, S.; Scherer, S.; Franz, C.M.; Heller, K.J. Growth inhibition of Listeria monocytogenes by bacteriocin-producing Staphylococcus equorum SE3 in cheese models. Food Control 2017, 71, 50-56. [CrossRef]

52. Zilelidou, E.A.; Skandamis, P.N. Growth, detection and virulence of Listeria monocytogenes in the presence of other microorganisms: Microbial interactions from species to strain level. Int. J. Food Microbiol. 2018, 277, 10-25. [CrossRef] [PubMed]

53. Büla, C.; Bille, J.; Glauser, M.P. An Epidemic of Food-Borne Listeriosis in Western Switzerland: Description of 57 Cases Involving Adults. Clin. Infect. Dis. 1995, 20, 66-72. [CrossRef]

54. Brauge, T.; Barre, L.; Leleu, G.; André, S.; Denis, C.; Hanin, A.; Frémaux, B.; Guilbaud, M.; Herry, J.-M.; Oulahal, N.; et al. European survey and evaluation of sampling methods recommended by the standard EN ISO 18593 for the detection of Listeria monocytogenes and Pseudomonas fluorescens on industrial surfaces. FEMS Microbiol. Lett. 2020, 367, 057. [CrossRef] [PubMed]

55. Fretz, R.; Sagel, U.; Ruppitsch, W.; Pietzka, A.T.; Stöger, A.; Huhulescu, S.; Heuberger, S.; Pichler, J.; Much, P.; Pfaff, G.; et al. Listeriosis outbreak caused by acid curd cheese 'Quargel', Austria and Germany 2009. Eurosurveillance 2010, 15, 19477. [CrossRef] [PubMed] 